\title{
THE ACM COMPUTER-CHESS CHALLENGE
}

\author{
Philadelphia, Penn. \\ February 10-17, 1996
}

\author{
M. Newborn ${ }^{1}$
}

\begin{abstract}
A six-game match between Garry Kasparov and DEEP BLUE will be held at the Philadelphia Convention Center, adjacent to the Marriott Hotel, in Philadelphia, Penn. Games will be played on the 10th, 11th, 13th, 14th, 16th, and 17th of February 1996, beginning at 3:00 p.m. Time controls are after 40 moves in two hours, followed by 20 moves in one hour, finally followed by 30 minutes for all remaining moves.
\end{abstract}

A prize of US $\$ 400,000$ will be offered to the winner and US $\$ 100,000$ to the loser. The event is being organized by the ACM Computer Chess Committee under the auspices of the ICCA. Mike Valvo will serve as the Umpire. The event is part of the ACM's Computing Week festival which will celebrate the 50th birthday of the modern electronic computer, designed at the University of Pennsylvania in Philadelphia.

For further information, contact Terry Phoenix at the ACM (212-869-7440 or phoenix@acm.org or Monty Newborn at 514-398-7079 or newborn@cs.mcgill.ca).

\section{THE ACM COMPUTER-CHESS WORKSHOP}

\section{RECENT ADVANCES IN COMPUTER CHESS}

\author{
Philadelphia, Penn. \\ February 16, 1996 \\ ICCA Communication by M. Newborn ${ }^{1}$
}

As part of ACM's Computing Week '96, a six-game match between the world chess champion Garry Kasparov and the world's top chess-playing computer DEEP BLUE is being held. On February 16, a workshop will be held, organized by the ACM Computer-Chess Committee, chaired by Professor Monty Newborn, with Professor Tony Marsland as the day's session Chairman. The title of the workshop is Recent Advances in Computer Chess.

By the time the workshop is held, four of the six games will have been played and we will have some insight into recent advances. These advances have taken place gradually over a thirty-year period and the evidence suggests that they will continue. Many advances have been tested at ACM computer-chess tournaments dating back to 1970 , and their programmers have presented their ideas at similar ACM workshops.

At this workshop, three papers will be presented, selected to be of interest of the chess community as well as to the computer community. Each paper will take up to 25 minutes to present, followed by questions and discussions. Two deal with the mechanics of searching chess trees. While the usual human vocabulary associated with playing chess is absent from these papers - the notions fork and pin may not appear nevertheless they deal with how to design strong chess-playing programs.

The first paper is by Jonathan Schaeffer and Aske Plaat; it is entitled New advances in alpha-beta searching. The alpha-beta algorithm is the main search algorithm used by chess programs as well as by programs that play other two-person games. Schaeffer has designed the world's leading checker-playing

\footnotetext{
1 McGill University, School of Computer Science, 805 Sherbrooke St. West, Montreal, Quebec H3A 2K6 Canada. Email: newborn@opus.cs.mcgill.ca.
} 
program, CHINOOK. It has taken on the world's best players and come out ahead. His and Plaat's paper focuses on ways to improve the efficiency of this important search algorithm. The more efficient the alpha-beta search, the larger the search space that can be examined in some allotted time; and of course, the larger the search space, the stronger the program.

Jean-Christophe Weill will present his work on parallel minimax search. It is entitled The ABDADA Distributed Minimax Search Algorithm. This work was performed within the framework of the leading chess program from France called FRENCHESS. Parallel search in the context of chess is a particularly exciting area for research, as it is a very difficult subject. How does one best keep hundreds or even thousands of soldiers busy looking in the woods for a pot of gold? But this problem is far simpler than that faced by programmers parallelizing the search of chess trees. Weill ran his experiments on 32 nodes of a CM5 computer.

The third paper is entitled A shogi-computer test set. Its authors, Hitoshi Matsubara, Hiroyuki lida and Jos W.H.M. Uiterwijk, have developed a set of positions that can be used to determine the strength of a shogi program. Shogi is very popular in Japan and has many of the same features as "western" chess although, typically, there are many more moves in each position in the search tree. This tends to make brute-force search look less attractive. For the time being, shogi programs are much weaker, relative to the top shogi players, than are chess programs. The authors contend that, once chess programs are playing better than the top players, there are other games that deserve attention from the AI community, in particular shogi. Of course, Go appears yet more difficult in some respects. The test set is similar to the Bratko-Kopec Test Set used by many of the chess programmers for testing their chess programs. The authors recommend those involved in developing shogi programs to adopt their set.

\title{
THE SIXTH HARVARD CUP HUMAN VERSUS COMPUTER CHESS CHALLENGE
}

\author{
27-28 December 1995 \\ New York, NY, USA \\ C. Chabris
}

Cambridge/USA

The Sixth Harvard Cup held at the Manhattan Conference Center, Fiterman Hall, 30 West Broadway in New York, will feature six of America's top grandmasters against eight of the leading microcomputer-based chess software packages in a team-match format. Each human will play each computer once, at a time control of a game in 25 minutes. There will be 48 games in all (two days $\times$ four rounds per day $\times$ six games per round), with play beginning at 5 p.m. each day. Demonstration boards and expert commentary will be provided, software will be exhibited, and T-shirts, chess books and equipment will be on sale. Admission for spectators is free and includes a copy of the official program book.

Currently expected to compete are grandmasters Joel Benjamin, Boris Gulko, Ilya Gurevich, Gregory Kaidanov, Michael Rohde and Patrick Wolff. The computer side will include the forthcoming CHESSMASTER 5000 and seven other programs, running on top-of-the-line desktop systems. (Note: if you are affiliated with a PC-based chess program that has not yet received an invitation, please contact cfc@h3.org as soon as possible. Thank you.)

The Harvard Cup Youth Challenge for students aged 5-18 will run each day from 9:30 a.m. to 4:30 p.m. Participants may register between 9:00 a.m. and 2:00 p.m. each day. Activities will include a series of challenge games against CHESSMASTER 5000 for prizes, chess lessons from top teachers, and demonstrations and workshops on how computers play chess.

1 HCC Associates, P.O. Box 2967, Harvard Square Station, Cambridge, MA 02238, USA. Email: cfc@isr.harvard.edu. 